\title{
The Updated Role of Ultrasound in Assessing Dermatological Manifestations in Systemic Sclerosis
}

\author{
Barbara Ruaro' \\ Tania Santiago ${ }^{2,3}$ \\ Michael Hughes ${ }^{4}$ \\ Gemma Lepri iD ${ }^{5}$ \\ Gabriele Poillucci ${ }^{6}$ \\ Elisa Baratella (iD ${ }^{6}$ \\ Francesco Salton ${ }^{\prime}$ \\ Marco Confalonieri iD \\ 'Unit of Pulmonology, University Hospital \\ of Trieste, Trieste, Italy; ${ }^{2}$ Department of \\ Rheumatology, Centro Hospitalare \\ Universitário de Coimbra, Coimbra, \\ Portugal; ${ }^{3}$ Medicine Faculty, University of \\ Coimbra, Coimbra, Portugal; \\ ${ }^{4}$ Department of Rheumatology, Royal \\ Hallamshire Hospital, Sheffield Teaching \\ Hospitals NHS Foundation Trust, \\ Sheffield, UK; ${ }^{5}$ Department of \\ Experimental and Clinical Medicine, \\ Division of Rheumatology, University of \\ Firenze, Florence, Italy; ${ }^{6}$ Department of \\ Radiology, Department of Medicine, \\ Surgery and Health Science, University of \\ Trieste, Trieste, Italy
}

Correspondence: Barbara Ruaro Unit of Pulmonology, University Hospital of Trieste, Trieste, Italy

Tel +393470502394

Email barbara.ruaro@yahoo.it

\begin{abstract}
Systemic sclerosis (SSc), an autoimmune connective tissue disease, characterized by skin fibrosis, increased dermal thickness and microvascular involvement. Fibroblasts and myofibroblasts deposit excessive amounts of collagenous and non-collagenous extracellular matrix components in the skin. This leads to microvascular abnormalities and Raynaud's phenomenon, with painful digital ulcers (DU) at the fingertips adding to patient discomfort. The skin involvement and severity in SSc was evaluated by the Modified Rodnan skin score (mRSS). Although high-frequency ultrasound (HUS) has been widely researched in the study of skin thickness and DU in SSc, its adoption into clinical practice is not yet common. However, novel insights into the still relatively unknown disease pathogenesis in SSc and its evaluation may be provided by HUS, including early (pre-clinical) skin involvement. It may also be useful in both the evaluation and follow-up of DU. Indeed, it is a non-invasive, safe, inexpensive and reproducible method able to assess not only SSc patients' cutaneous structural changes, but also their vascular system changes. Moreover, several recent studies have reported that elastosonography (ES) is of use when investigating skin involvement in systemic sclerosis. This review aims at providing information as to role HUS and ES play in research advancements and the clinical perspectives in the evaluation of skin thickness and DU in SSc patients.
\end{abstract}

Keywords: systemic sclerosis, ultrasound, elastosonography, skin, skin thickness, digital ulcers

\section{Introduction}

The assessment of skin involvement in SSc is not only pivotal in making an initial diagnosis, but also has a prognostic relevance, as there is an inverse correlation between the severity of skin involvement, survival and prognosis. ${ }^{1-6}$ Indeed, quantifying skin impairment provides vital information, such as an assessment of disease activity and severity, an evaluation of therapy response and a management guide. ${ }^{1-6}$

Systemic sclerosis skin impairment goes through three phases, ie, edematous, fibrotic and atrophic. The first phase (edematous) is characterised by painless pitting oedema of the hand and finger, which may also affect the feet, legs, face and forearms. The passage to the second, long, fibrotic phase is often a fast process and involves a reduction in skin elasticity. This is characterised by hard, shiny and taut skin, adherent to the sub-cutis. The last phase (atrophic) involves thinning of the skin, which binds to the underlying tissue. ${ }^{1,7-11}$ 
The observation of skin manifestations is often used in clinical practice to classify the disease into two subsets, ie, limited or diffuse cutaneous skin involvement. ${ }^{1-5}$ The damage observed in limited cutaneous skin involvement (lcSSc) is confined to the extremities, ie, the hands, forearms, feet, legs and face, whilst it is present on the arms, chest, abdomen and thighs in diffuse cutaneous skin involvement (dcSSc). ${ }^{1-5}$

The mRSS is the only validated method able to recognise and study the skin manifestations and the skin involvement severity in SSc. ${ }^{1-5,12}$ Rodnan et al developed the original score in $1979^{13}$ and it is used for the primary outcome in most clinical trials by the evaluation of skin thickness. It is feasible, reliable, valid and responsive to change in multicenter clinical trials, especially in dcSSc.

The mRSS sums the ratings obtained from the clinical palpation of seventeen skin areas (zygoma, fingers, dorsum of the hands, forearms, arms, chest, abdomen, thighs, legs and feet). ${ }^{13-17}$ The skin thickness is assessed by palpation and rated from 0 (normal), 1 (weak), 2 (intermediate) to 3 (severe skin thickening). The total score provides the sum of the individual skin assessments in the selected body areas, which are scored from 0 (normal skin thickness in the entire body) to 51 (severe skin thickness in all the 17 areas), the score increases with the extent and severity of the skin thickening. However, mRSS is hampered by its dependence on the examiner's skill, who must be specifically trained and experienced. Moreover, other drawbacks include the fact that it is unable to differentiate between skin thickness and tightness, has a high intra- and interobserver variability (12\% and $25 \%$, respectively) and cannot detect small, but clinically relevant, changes in skin thickness over time. Although the peak involvement time has not yet been clearly defined, the mRSS score tends to worsen in the early phase of the disease to improve in the late phase. $^{13-18}$
Several studies have reported that high-frequency skin ultrasound (HUS) can make an early identification of skin involvement in SSc patients. ${ }^{18-31}$ Alexander and Miller measured skin thickness using a $15 \mathrm{MHz}$ ultrasound probe as early as $1979 .{ }^{22}$ As the study of skin thickness necessitates a high frequency with a good resolution, most researchers have used an 18-32 MHz probe, although there are a few exceptions where higher $(50 \mathrm{MHz})$ frequency transducers have been used. ${ }^{42}$ Although the $18-32 \mathrm{MHz}$ probe has a poor penetration, it does provide a good visualization and distinguishes epidermis, dermis and subcutaneous fat (Figure 1). However, most authors have made comparisons between mRSS and HUS. Although most data did not evidence any correlation between the local mRSS and the HUS findings, a correlation with global mRSS was reported by some authors. ${ }^{27-29}$ HUS provides a range of values that determine dermal thickness and can be compared with the semi-quantitative mRSS scale with only 4 integer values and for the identification of different skin layers. HUS and mRSS evaluate different skin properties, ie, mRSS evaluates skin impairment, texture and fixation, whilst HUS distinguishes the different skin layers and makes a precise evaluation of dermal thickness. ${ }^{27-29}$ HUS also offers several benefits over mRSS, as it is a reliable, reproducible method able to assess dermal thickness (intra- and inter-observer variability, $4 \%$ and $8 \%$, respectively) and its scoring system may be a useful outcome measure, particularly in clinical trials. ${ }^{18-20,33}$ Moreover, not only does HUS allow for early detection of skin involvement, but it has also been demonstrated that the HUS dermal thickness values correlate with the clinical phase. ${ }^{18-20}$

However, also HUS has its drawbacks, as, like mRSS the operator must be trained and well versed in the correct use of the machine (ie, setting, probe position and hand pressure). Moreover, a HUS evaluation of the set 17 points
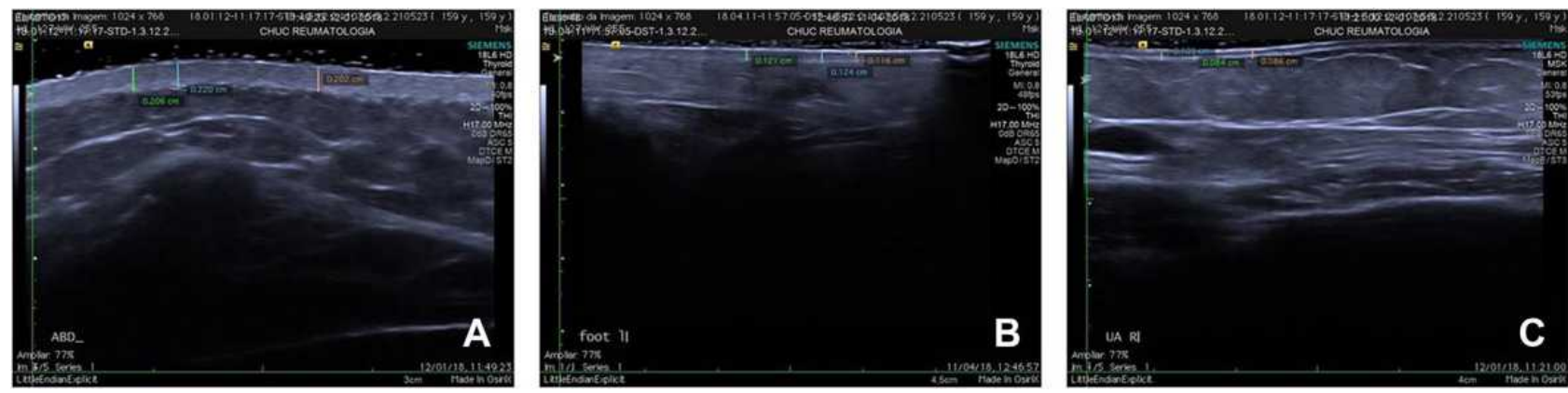

Figure I High-frequency ultrasound, I8-MHz, B-mode, at the upper arm (A), abdomen (B), foot (C) in a patient with systemic sclerosis. Note: Figure courtesy of Tânia Santiago. 
takes longer than one done by mRSS (15-20 minutes against 5 minutes for each patient). ${ }^{31}$ Despite this, HUS does offer some advantages, such as the possibility of storing images for future evaluation and it is more sensitive in detecting skin involvement in the early stages. Therefore, it can potentially provide a valuable contribution to clinical assessment, especially when it comes to research into the pathogenesis and treatment of this puzzling disease.

The first study reporting the use of HUS to evaluate localized scleroderma was published in 1991 and others followed. HUS is able to evidence increases in dermal thickness and echogenicity in active lesions and transducers with a frequency from 6 to $20 \mathrm{MHz}$ are most commonly used. ${ }^{34-37}$ It has also been demonstrated to have a good sensitivity in detecting localized scleroderma lesions and change over time. ${ }^{34-37}$

The utility of elastosonography (ES) to investigate scleroderma skin impairment has recently been reported, with different data as to its correlation with the HUS evaluation: However, as stated by Delle Sedie et al, this may be accounted for by the fact that the machines and software used differed. ${ }^{27}$ ES evaluates tissue elasticity, which, as aforementioned, is reduced in SSc due to the presence of skin fibrosis, and provides a colour scale which is superimposed on the HUS grey scale image. Like the aforementioned techniques, ES is very timeconsuming, operator dependent and its use requires specific training. ${ }^{38-40}$ Although it has been proposed that other clinical tools, such as magnetic resonance imaging, optical coherence tomography, plicometer and durometry, are able to make a clinical evaluation of skin involvement in $\mathrm{SSc}$ patients, literature data is still scanty. ${ }^{12,23,26,31}$

Recently, HUS has also been used to evaluate digital ulcers (DU) in SSc patients. ${ }^{41}$

This review aims at providing updated information extrapolated from studies that used HUS or ES to detect/ follow skin impairment and digital ulcers in systemic sclerosis and localized scleroderma.

\section{Recent Acquisitions in the Use of Ultrasound in the Study of Skin in Systemic Sclerosis}

A 2017 study demonstrated that high-frequency ultrasound is able to identify subclinical diffuse dermal involvement in lcSSc patients. Dermal thickness (DT) was evaluated by both HUS and mRSS at the usual 17 skin areas (zygoma, fingers, dorsum of the hands, forearms, upper arms, chest, abdomen, thighs, lower legs and feet). The study reported a higher DT in lcSSc than in healthy subjects in 4 to 6 skin areas with normal mRSS, in contrast with the diagnosis of $1 \mathrm{cSSc}$ (arm, chest and abdomen $)^{20}$ (Table 1). A comparison between HUS and mRSS was also made and it was reported that HUS is able to make an earlier identification of skin involvement than mRSS. Moreover, another study reported that it is able to identify the edematous phase that precedes palpable skin involvement in early disease, which aids a diagnosis of precocious diffuse skin involvement. ${ }^{21}$ Microarray gene expression studies are in agreement with these data, leading to the hypothesis that clinically unaffected skin shares the same gene signatures and pathology as that of clinically affected skin in SSc. Moreover, a recent study observed a statistically significant relationship between the percentage of circulating fibrocytes and DT. This was evidenced by both mRSS and HUS (equipped with $22 \mathrm{MHz}$ and $18 \mathrm{MHz}$ probes), in $1 c S S c .{ }^{8}$ No correlations between mRSS or DT-HUS and the percentage of circulating fibrocytes were observed in the control group. ${ }^{8}$

In 2019, Ruaro et al confirmed high frequency is capable of providing a resolution able to distinguish the different skin layers. ${ }^{33}$ This study compared the performance of 2 high-range ultrasound transducers $(18 \mathrm{MHz}$ and 22 $\mathrm{MHz}$ ), in the evaluation of subclinical dermal thickness (DT) changes in limited cutaneous systemic sclerosis (lcSSc) patients. ${ }^{33}$ The authors concluded by suggesting that a $22 \mathrm{MHz}$ HUS probe is more sensitive in detecting subclinical DT changes than an $18 \mathrm{MHz}$ probe. ${ }^{33}$ They also confirmed that skin high-frequency HUS is able to detect subclinical dermal involvement also in the clinically unaffected skin areas of $\mathrm{lcSSc}$ patients. The same group assessed whether there were any correlations between microvascular damage, evaluated by nailfold videocapillaroscopy and skin impairment. They compared 3 different methods in SSc patients, ie, the mRSS, HUS and the plicometer skin test (PST). ${ }^{31}$ All 3 methods demonstrated a progressively higher skin impairment in the "Early", "Active" or "Late" pattern of nailfold microangiopathy (for mRSS p-value $<0.01$, HUS $\mathrm{p}$-value $<0.02$ and PST $\mathrm{p}$-value $<0.02)$. There was a positive correlation in $\mathrm{SSc}$ patients between the three methods ( $p$-value $<0.0001$ ). This study concluded by reporting a correlation between two of the most important aspects in the classification and monitoring of SSc patients, ie, microvascular damage 
Table I Recent Milestones in the Study of Skin Ultrasound, Analysed by Skin High-Frequency Ultrasound in Systemic Sclerosis

\begin{tabular}{|c|c|c|c|c|}
\hline First Author & $\begin{array}{l}\text { Study } \\
\text { Type }\end{array}$ & $\begin{array}{l}\text { SSc } \\
\text { Patients } \\
\text { (n) }\end{array}$ & $\begin{array}{l}\text { Control } \\
\text { Population }\end{array}$ & Summary of Results \\
\hline Sulli et al $(2014)^{20}$ & $\mathrm{CC}$ & $\begin{array}{l}43 \mathrm{lcSSc} \\
14 \mathrm{dcSSc}\end{array}$ & $37 \mathrm{HC}$ & $\begin{array}{l}\text { A positive correlation was observed between nailfold microvascular damage } \\
\text { severity and both ultrasound-DT ( } p \text {-value }=0.028 \text { ) and mRSS values } \\
\text { ( } p \text {-value }<0.000 \mathrm{I} \text { ). } \\
\text { This study demonstrates a relationship between nailfold microangiopathy severity, } \\
\text { DT and blood perfusion, in SSc patients }\end{array}$ \\
\hline Sulli et al $(2017)^{30}$ & $\mathrm{CC}$ & $50 \mathrm{IcSSc}$ & $50 \mathrm{mHC}$ & $\begin{array}{l}\text { This study strongly supports that subclinical dermal involvement may be } \\
\text { detectable by US, even in skin areas with a normal mRSS, in patients classified as } \\
\text { having IcSSc. }\end{array}$ \\
\hline Ruaro et al $(2018)^{31}$ & $\mathrm{CC}$ & $\begin{array}{l}45 \mathrm{lcSSc} \\
17 \mathrm{dcSSc}\end{array}$ & $62 \mathrm{mHC}$ & $\begin{array}{l}\text { This study demonstrates, for the first time, a significant inverse relationship } \\
\text { between skin BP, measured by LASCA and DT, evaluated by both US and mRSS, in } \\
\text { SSc patients. All measurements were taken at the level of dorsum of the middle } \\
\text { phalanx of the third fingers. }\end{array}$ \\
\hline Ruaro et al $(2019)^{32}$ & $\mathrm{CC}$ & $\begin{array}{l}40 \mathrm{lcSSc} \\
23 \mathrm{dcSSc}\end{array}$ & $63 \mathrm{mHC}$ & $\begin{array}{l}\text { This study demonstrates a correlation between two of the most important } \\
\text { aspects in the classification and monitoring of SSc patients. That is microvascular } \\
\text { damage progression (evaluated by NVC) and skin damage (assessed by mRSS, US } \\
\text { and PST) }\end{array}$ \\
\hline Ruaro et al $(2019)^{33}$ & $\mathrm{CC}$ & $48 \mathrm{IcSSc}$ & $48 \mathrm{mHC}$ & $\begin{array}{l}\text { The } 22 \mathrm{MHz} \text { US probe is more sensitive in detecting subclinical DT changes than } \\
\text { is an } 18 \mathrm{MHz} \text { probe } \\
\text { Subclinical dermal involvement is detectable by skin high frequency US, also in the } \\
\text { clinically unaffected skin areas of IcSSc patients }\end{array}$ \\
\hline $\mathrm{Li}$ et al $(2018)^{42}$ & CS & $31 \mathrm{SSc}$ & $31 \mathrm{mHC}$ & $\begin{array}{l}\text { These authors also demonstrated a positive correlation between skin damage, } \\
\text { evaluated in five different sites, ie the dorsal of the forearm, hand, finger, leg and } \\
\text { manubrium, and disease activity }\end{array}$ \\
\hline Naredo et al $(2020)^{43}$ & $\mathrm{CC}$ & $\begin{array}{l}40 \mathrm{lcSSc} \\
23 \mathrm{dcSSc}\end{array}$ & $6 \mathrm{HC}$ & $\begin{array}{l}\text { A } 50 \mathrm{MHz} \text { probe provides better resolution and visualization of the derma, } \\
\text { allowing for a more accurate DT determination and a correct assessment of the } \\
\text { different skin layers. } \\
\text { DT was significantly higher in SSc patients than in the control group ( } \mathrm{p} \text {-value } \\
<0.05) \text {. } \\
\text { Moreover, a texture computed analysis of the dermis and hypodermis } \\
\text { discriminated SSc from healthy subjects. }\end{array}$ \\
\hline Chen et al $(2020)^{44}$ & $\mathrm{CC}$ & $44 \mathrm{SSc}$ & $22 \mathrm{HC}$ & $\begin{array}{l}\text { There was good agreement between the ultrasound-measured skin thickness and } \\
\text { the histological skin thickness, in } 9 \mathrm{dcSSC} \text { and } 4 \text { IcSSc patients. }{ }^{44}\end{array}$ \\
\hline
\end{tabular}

Abbreviations: CC, case-control study; CS, cross-sectional study; mHC, age- and gender-matched healthy controls; LASCA, laser speckle contrast analysis; PST, plicometer skin test; dcSSc, diffuse cutaneous systemic sclerosis; IcSSc, limited cutaneous systemic sclerosis; SSc, systemic sclerosis.

progression (evaluated by nailfold videocapillaroscopy, NVC) and skin damage (assessed by mRSS, HUS and PST). $^{31}$

Interestingly, two recent studies have also demonstrated a correlation between dermal thickness and peripheral blood perfusion. ${ }^{20,32}$ The first one ${ }^{20}$ reported a relationship between nailfold microangiopathy severity, DT and fingertip blood perfusion (FBP) in SSc patients. There was a positive correlation between nailfold microvascular damage severity and both ultrasound-DT ( $p$-value $=0.028)$ and mRSS values $(p$-value $<0.0001)$. Moreover, both ultrasound-DT and mRSS gave progressively higher values in "Early", "Active" or "Late" NVC microangiopathy patterns. There was a negative correlation between the nailfold microvascular damage severity and FBP (p-value $<0.0001$ ), demonstrating that patients with a more advanced NVC pattern had the lowest FBP. FBP and both ultrasound-DT (p-value $=0.007)$ and mRSS 
values also had a negative correlation ( $\mathrm{p}$-value $=0.0002$ ) Another observation was a higher ultrasound-DT in SSc patients at the finger level and a lower FBP than what was observed in the healthy subjects ( $p$-value $<0.0001) .{ }^{20}$ The aim of the authors of the second study ${ }^{32}$ set was the identification of any correlations between skin blood perfusion (BP) and dermal thickness (DT) in different skin areas of SSc patients. They reported a statistically significant negative correlation in SSc patients between skin BP and both ultrasound-DT ( $\mathrm{p}$-value $=0.0005 \mathrm{r}=0.43$ ) and mRSS ( $p$-value $=0.0007 \mathrm{r}=0.42$ ) at the level of the finger dorsum but not at the level of the hand dorsum or zygoma. No statistically significant correlation was observed between skin BP and ultrasound-DT at any level in healthy subjects (HS). Indeed, when SSc patients were compared to HS, a statistically significant lower BP was observed only at the finger level (the median PU was 72.6 vs 136.1, respectively, $\mathrm{p}$-value $<0.0001$ ) along with a statistically significant higher ultrasound-DT at the level of dorsum of 3rd finger bilaterally (median $\mathrm{mm} 0.9$ vs 0.7 , p-value $<0.0001$ ), dorsum of hands (median mm 0.9 vs 0.7 , p-value $<0.0001$ ) and zygoma (median $\mathrm{mm} 0.8$ vs 0.7 , $\mathrm{p}$-value $<0.0001$ ). There was a significant positive correlation between ultrasound-DT and mRSS in SSc patients at the level of the dorsum of the fingers $p$-value $<0.0001$ $r=0.51$; the dorsum of hands ( $p$-value $=0.03 r=0.27$ ) and zygoma ( $\mathrm{p}$-value $=0.0001 \mathrm{r}=0.45$ ). There was a correlation between the progressive decrease in skin BP and the increase in ultrasound-DT with the progression of the severity of NVC patterns. This study was the first to demonstrate a significant inverse relationship between skin BP measured by laser speckle contrast analysis (LASCA) and DT and evaluated by both HUS and mRSS, at the level of dorsum of the middle phalanx of the third fingers, in SSc patients. ${ }^{32}$

Li et al prospective cross-sectional study confirmed that skin high-frequency ultrasound, equipped with an 18$\mathrm{MHz}$ ultrasonic probe, evaluated subclinical dermal involvement in $31 \mathrm{SSc}$ patients and in 31 age and sex-matched healthy controls. They also reported that there was a positive correlation between skin damage, evaluated in the dorsal of the forearm, hand, finger, leg and manubrium, and disease activity. ${ }^{42}$ Naredo et al confirmed that HUS, with a $50 \mathrm{MHz}$ probe, provides a better resolution and visualization of the derma, making for a more accurate DT determination and correct assessment of the different skin layers that showed a notable difference between the dermis and hypodermis texture of SSc and healthy subjects. ${ }^{43}$
Indeed, an evaluation was made of the DT at the level of forearm, hand and fingers in $21 \mathrm{SSc}$ patients and 6 healthy controls. The three experts involved concluded that there was a statistically significantly higher DT in the SSc patients than in the control group (P-value $<0.05$ ). Moreover, a texture computed analysis of the dermis and hypodermis was able to discriminate SSc from healthy subjects. $^{43}$

Recently, Chen et al evaluated 13 patients $(9 \mathrm{dcSSc}$ and $4 \mathrm{lcSSc}$ ) and performed a skin ultrasound evaluation and skin biopsy at the same level, ie, the dorsal and forearms. They observed a good correlation between the skin thickness evaluated by ultrasound and the histological skin thickness $(\mathrm{r}=0.6926$, P-value $=0.009)$. Ultrasoundmeasured skin thickness showed good agreement with the histological skin thickness. ${ }^{44}$

\section{Recent Acquisitions in the Use of Ultrasound in the Study of Localized Scleroderma}

Skin ultrasound allows a follow-up of LS lesions and has been proposed as a non-invasive, real-time imaging technique to assess and monitor the severity of localized scleroderma (LS) $)^{35,37,45-53}$ (Table 2). As far back as 30 years ago, it was recommended that B-mode skin ultrasound be used in clinical practice to evaluate LS patients. Moreover, as it is able to detect skin lesion progression or regression, it was also suggested that it plays a pivotal role in patient follow-up. ${ }^{35}$ There have been numerous technological advances in HUS probes over the last few decades and the potential of this examination in routine care has been confirmed, allowing for the assessment of the thickness and activity of morphea lesions. ${ }^{49}$

The application of 14-MHz HUS examination to LS lesions suggested an association of hyperechogenicity with the presence of moderate/extensive sclerosis. ${ }^{49}$ Conversely, some studies reported atrophic lesions as hypoechogenic. The inflammatory phase appears to be characterized by abnormal echogenicity patterns, mainly involving the dermis, hypodermis and the deep tissue layers of LS lesions. Moreover, skin HUS assessment allows for a simultaneous evaluation of cutaneous blood flow. ${ }^{47,53}$

A recent study, carried out by Pérez et al, reported the presence of a significantly lower dermis and hypodermis thickness in the layers of LS lesions, compared to the healthy skin of 13 LS patients, aged $\leq 18$. Only one patient had tissue thickening, which probably reflected the active 
Table 2 The Main Characteristics of the Studies Using Ultrasound for the Study of Localized Scleroderma

\begin{tabular}{|c|c|c|c|c|}
\hline First Author & $\begin{array}{l}\text { Study } \\
\text { Type }\end{array}$ & $\begin{array}{l}\text { SSc Patients } \\
\text { Number/Total } \\
\text { Skin Lesions }\end{array}$ & $\begin{array}{l}\text { Control Population } \\
\text { Number }\end{array}$ & Main Findings \\
\hline $\begin{array}{l}\text { Perez et al } \\
(2020)^{50}\end{array}$ & CS & $\begin{array}{l}\text { I3 patients (median } \\
\text { age: } 10 \text { y) Total skin } \\
\text { lesions: } 13\end{array}$ & $\begin{array}{l}\text { Control was represented by } \\
\text { corresponding healthy skin of } \\
\text { enrolled patients }\end{array}$ & $\begin{array}{l}\text { - A significantly lower dermal thickness and hypodermis in } \\
\text { LS lesions compared to healthy skin } \\
\text { - Only one patient (active LS) had skin thickening } \\
\text { - 7//3 subjects had echogenic changes }\end{array}$ \\
\hline $\begin{array}{l}\text { Ranosz-Janicka } \\
(2019)^{51}\end{array}$ & $\mathrm{CC}$ & $\begin{array}{l}40 \text { adult patients. } \\
\text { Total skin lesions: } \\
92\end{array}$ & Site-matched unaffected skin & $\begin{array}{l}\text { - An increase in the dermal thickness in all erythematous } \\
\text { and sclerotic lesions } \\
\text { - A decrease in the dermal thickness in } 94.3 \% \text { of atrophic } \\
\text { lesions. } \\
\text { - Dermal hyperechogenicity in } 96 \% \text { of sclerotic lesions } \\
\text { and } 91.4 \% \text { of atrophic lesions }\end{array}$ \\
\hline $\begin{array}{l}\text { Porta et al } \\
(2014)^{34}\end{array}$ & $\mathrm{CC}$ & $\begin{array}{l}\text { I0 juvenile LS } \\
\text { patients }\end{array}$ & $\begin{array}{l}\text { Normal skin in the } \\
\text { contralateral area }\end{array}$ & $\begin{array}{l}\text { - An increase in dermal thickness of involved areas } \\
\text { compared to normal contralateral areas } \\
\text { - The data from this study suggest that treatment } \\
\text { response may be monitored by skin ultrasound }\end{array}$ \\
\hline $\begin{array}{l}\text { Weibel et al } \\
(2020)^{52}\end{array}$ & $\mathrm{CC}$ & $\begin{array}{l}24 \text { patients (age at } \\
\text { start of treatment } \\
9.6 \mathrm{y})\end{array}$ & $\begin{array}{l}\text { The unaffected contralateral } \\
\text { side }\end{array}$ & $\begin{array}{l}\text {-Baseline (start of treatment):a slight decrease in the } \\
\text { median dermal thickness and increase in dermal } \\
\text { echogenicity in LS area compared to the contralateral } \\
\text { healthy side } \\
\text { - Weak positive correlation of dermal thickness and } \\
\text { negative correlation of dermal echogenicity with clinical } \\
\text { score }\end{array}$ \\
\hline Arisi et al $(2019)^{45}$ & $\mathrm{CC}$ & 17 adult patients & $\begin{array}{l}\text { Healthy skin contiguous to } \\
\text { morphea lesions }\end{array}$ & $\begin{array}{l}\text { - An increase in dermal thickness and a decrease in } \\
\text { echogenicity of affected skin } \\
\text { - "Yoyo" figures were detected in } 47 \% \text { of affected skin } \\
\text { areas and only in } 5.9 \% \text { of the healthy skin ( } p \text {-value }=0.02 \text { ) } \\
\text { - The data from this study support the utility of US in } \\
\text { patient follow-up to monitor treatment response }\end{array}$ \\
\hline $\begin{array}{l}\text { Murray et al } \\
(2016)^{48}\end{array}$ & CS & 32 adult patients & $\begin{array}{l}\text { Unaffected skin sites in the } \\
\text { same enrolled patients }\end{array}$ & $\begin{array}{l}\text { - An increase in epidermal thickness in the affected site } \\
\text { compared to the unaffected site (in active morphea } \\
\text { plaques, }(- \text { value }=0.03) \text { ) }\end{array}$ \\
\hline
\end{tabular}

Abbreviations: CC, case-control study; CS, cross-sectional study; LS, localized scleroderma.

phase of the skin lesion, that was erythematous and warm at clinical examination. The same study reported an increased echogenicity of the hypodermis and in three cases also in the dermal layer of the LS lesions, in 7 patients. ${ }^{50}$

Ranosz-Janicka et al made a high-frequency HUS (20 $\mathrm{MHz}$ probe) evaluation of a total of 92 LS lesions in 40 adult patients and reported a dermal thickness increase in all erythematous and sclerotic lesions. ${ }^{51}$ Conversely, there was a decrease in dermal thickness in 33/35 atrophic plaques. Most of the sclerotic and atrophic lesions had an increased echogenicity and the presence of hyperechogenicity was associated to the inflammatory phase, which was present in
$96.8 \%$ of all the erythematous lesions. ${ }^{51}$ Taken as a whole, the data from this study implies a correlation between the HUS findings and the clinical evaluation and reports a highfrequency HUS sensitivity of $97 \%$ and a $90 \%$ specificity. ${ }^{51}$

Porta et al made a HUS (18 MHz linear probe) evaluation of 10 young LS patients, reporting a dermis thickness increase in LS lesions compared to healthy skin. Moreover, these authors confirmed that there might be role for HUS in post-treatment patient follow-up. Indeed, there was a decrease in the mRSS after treatment in 7 patients, which was associated to a dermal thickness decrease in $6 / 7 .^{34}$ 
This study seems to confirm the strategic role skin HUS plays in patient follow-up, in particular in the monitoring of treatment response.

In the same context, Weibel et al recently made a high-frequency HUS (20 MHz) investigation into the efficacy of systemic treatment with corticosteroids and methotrexate in children with LS. They reported no statistically significant difference in either dermal thickness or echogenicity during the study period and only a weak positive correlation for dermal thickness and a negative correlation for dermal echogenicity, with the clinical activity score. $^{52}$

Arisi et al analysed 40 plaques from 26 LS patients using a $13-\mathrm{MHz}$ HUS probe. They proposed that dense images "resembling a yoyo" were a characteristic HUS feature in morphea. ${ }^{46}$ The presence of these abnormalities in LS patients, confirmed by high-frequency HUS (50 $\mathrm{MHz}$ ), led them to conclude that this technique was a suitable examination in patient follow-up. Indeed, at baseline, the authors reported a significant dermal thickness increase in LS lesions in all patients, along with an echogenicity reduction, whilst there was no statistically significant difference in epidermal thickness. HUS revealed a post-UVA1 treatment improvement in dermal hypoechogenic bands and a significant decrease in yoyo images. ${ }^{45}$ As aforementioned, echogenicity changes may also help to distinguish active LS skin lesions from inactive ones. Li et al evaluated 21 pediatric LS patients with HUS (8-14 MHz) (32 scans of active lesions and 20 scans of inactive ones) and observed that active lesions seemed to be more echogenic than inactive ones, with a statistically significant difference in the hypodermis and deep tissue layers. No statistically significant differences were observed between active and inactive LS skin lesions in the dermal thickness score, hypodermis or deep tissue layer. ${ }^{37}$ Moreover, a study carried out using HUS (7-15 MHz) evidenced a subcutaneous tissue echogenicity and increased cutaneous blood flow. The authors stated that this seemed to characterize active morphea lesions, with a $100 \%$ sensitivity and specificity. ${ }^{53}$

A study on 32 morphea sufferers, investigated by highfrequency HUS, revealed an epidermal thickness increase from the centre of the active morphea plaque to the uninvolved site, whilst no statistical difference was observed in dermal thickness. ${ }^{48}$

Therefore, it seems that the available studies on skin HUS support the potential role of this technique in LS patients and encourage its use in clinical practice. Indeed,
HUS complements clinical assessment in the evaluation of skin lesions and may be of help in distinguishing active lesions from quiescent ones. Moreover, it provides an easily documentable and repeatable objective assessment, making it useful to monitor treatment response and/or lesion progression in patient follow-up.

\section{Recent Acquisitions in the Use of Elastography Ultrasound in the Study of Skin in Systemic Sclerosis}

Ever increasing attention has been paid to elastography ultrasound in the quantitative assessment of skin involvement in SSc, over the last decade (Table 3). Indeed, numerous studies have reported on skin stiffness based on manual compression ${ }^{38,39,54,55}$ and shear-wave elastography. ${ }^{44,56-61}$ Most of these studies reported a significantly higher shear-wave velocity value in SSc patients than in controls, at almost all the Rodnan skin sites (Table 3). Interestingly, four of these studies observed a significantly higher skin stiffness in clinically uninvolved skin, ie, with an mRSS score of 0 , in SSc than in healthy controls. ${ }^{5,5,6,6,10,11}$ Santiago et al 5-year followup study ${ }^{62}$ reported a statistically significant decrease in skin stiffness at all the mRSS sites, in SSc patients (excepted at the finger level) compared to controls, over time. This finding suggests that shear-wave elastography is more sensitive to time-related change than is mRSS. Recently, Victoria et al demonstrated a strong correlation between ultrasound-skin thickness and shear-wave elastography with dermal collagen deposition, at the dorsal forearm. ${ }^{61}$

Taken on the whole, the aforementioned studies emphasize the fact that elastography ultrasound, particularly shear-wave elastography, has a potential role as a complementary tool in skin evaluation in $\mathrm{SSc}$ (Figure 2). However, their methodology, protocols, number and definition of skin sites to be examined differ and there is no robust data as to reproducibility and feasibility. Therefore, further research should be carried out on early disease diagnosis, disease monitoring and the evaluation of treatment response. If this goal is to be met, skin ultrasound assessment protocols require standardization so as to be able to better explore further research, particularly when it comes to the validation of skin ultrasound as a surrogate in future SSc clinical trials and clinical practice. 
Table 3 The Main Characteristics of the Studies Using Ultrasound Elastography

\begin{tabular}{|c|c|c|c|c|}
\hline $\begin{array}{l}\text { First } \\
\text { Author }\end{array}$ & $\begin{array}{l}\text { Study } \\
\text { Type }\end{array}$ & $\begin{array}{l}\text { SSc Patients } \\
\text { (n) }\end{array}$ & $\begin{array}{l}\text { Control } \\
\text { Population } \\
\text { (n) }\end{array}$ & Main Findings \\
\hline $\begin{array}{l}\text { lagnocco } \\
(2010)^{38}\end{array}$ & CC & $\begin{array}{l}18 \\
(10 d c S S c ; 811 c S S c)\end{array}$ & $15 \mathrm{mHC}$ & $\begin{array}{l}\text { - Blue areas in subjects; never detected in controls in forearm; not in fingers. } \\
\text {-Changes independent of clinical evidence of skin involvement. }\end{array}$ \\
\hline $\begin{array}{l}\text { Di Geso } \\
(2011)^{39}\end{array}$ & CS & $\begin{array}{l}22(14|c S S c| \\
18 \mathrm{dcSSc})\end{array}$ & - & - Elastography can improve the reliability of the US dermal thickness at finger in SSc patients. \\
\hline $\begin{array}{l}\text { Cannao } \\
(2014)^{54}\end{array}$ & $\mathrm{CC}$ & 6 & 6 & $\begin{array}{l}\text { - Stiffer tissue (from a semi-quantitative scale in which lower levels corresponded to harder tissues) } \\
\text { compared with controls: total median score } 6(4-6) \text { vs II (9-1I) p-value }<0.00 \text { I }\end{array}$ \\
\hline $\begin{array}{l}\text { Hou } \\
(2015)^{56}\end{array}$ & CC & $15 \mathrm{dcSSc}$ & $15 \mathrm{mHC}$ & $\begin{array}{l}-S W V \text { values were higher in dcSSc than in controls at the hands, forearms and feet }(p \text {-value }<0.05) \\
-S W V \text { values of uninvolved skin were higher than those of controls }(p<0.00 I) \\
-S W V \text { values increased with increasing skin scores except for skin score } 3(p<0.05)\end{array}$ \\
\hline $\begin{array}{l}\text { Santiago } \\
(2016)^{57}\end{array}$ & CC, $\mathrm{P}$ & $\begin{array}{l}26(13 \mathrm{dcSSc}, \\
13 \mathrm{lcSSc})\end{array}$ & $17 \mathrm{mHC}$ & $\begin{array}{l}\text { - SWV values were significantly higher in SSc than in controls in } 11 / 16 \text { mRSS sites } \\
\text { - SWV values were strongly correlated with the local mRSS in the forearm, hand, phalanx and thigh } \\
\text { - In SSc, clinically unaffected skin could also be differentiated from healthy skin from controls }\end{array}$ \\
\hline $\operatorname{Liu}(2017)^{58}$ & CC & $28 \mathrm{dcSSc}$ & $15 \mathrm{mHC}$ & $\begin{array}{l}\text { - ARFI quantification was significantly higher in hyperechoic than isoechoic }(p<0.001) \text {. The mRSS were } \\
\text { significantly higher in hyperechoic and/or hypoechoic than isoechoic }\end{array}$ \\
\hline $\begin{array}{l}\text { Çildağ } \\
(2017)^{55}\end{array}$ & CS & $40 \mathrm{dcSSc}$ & - & $\begin{array}{l}\text { - No patients had a red pattern (group I); } 14 \text { had a green pattern (group } 2 \text { ) and } 26 \text { had a blue pattern } \\
\text { (group 3). } \\
\text {-The color-scale groups had a statistically significant difference in duration of disease ( } \mathrm{p} \text {-value }=0.013 \text { ). }\end{array}$ \\
\hline $\begin{array}{l}\text { Yang } \\
(2018)^{59}\end{array}$ & CC & $\begin{array}{l}37 \\
(14 \mathrm{lcSSc}, 23 \mathrm{dcSSc})\end{array}$ & 37 & $\begin{array}{l}\text { - Skin elastic modulus values (E-score) were significantly higher in SSc patients than controls, at all } \\
\text { measured sites ( } \mathrm{p} \text {-value }<0.00 \mathrm{I}) \text {. } \\
\text { - mRSS correlated more closely with skin stiffness }(r=0.889 \text {, } \mathrm{p} \text {-value }<0.00 \mathrm{I}) \text { than with ST }(r=0.465 \text {, } \\
\mathrm{p} \text {-value }=0.002) \text {. }\end{array}$ \\
\hline $\begin{array}{l}\text { Sobolewski } \\
(2020)^{60}\end{array}$ & CC & $\begin{array}{l}40 \text { (29lcSSc; } \\
\text { I I dcSSc) }\end{array}$ & 28 & $\begin{array}{l}\text { - The elastographic strain was significantly higher than in controls, in SSc patients } \\
\text { with normal mRSS values } \\
\text { - SWE in the fingers is highly accurate to distinguish SSc patients } \\
\text { - SWE values were more reproducible than those of the mRSS clinical examination } \\
\text { (ICC } 0.987 \text { vs } 0.94 I \text { ) }\end{array}$ \\
\hline $\begin{array}{l}\text { Santiago } \\
(2020)^{62}\end{array}$ & CC & $\begin{array}{l}21(121 \mathrm{lcSSc} ; \\
9 \mathrm{dcSSc})\end{array}$ & 15 & $\begin{array}{l}\text { - There was a significant decrease over time. in the skin stiffness at all Rodnan sites ( } \mathrm{p} \text {-value } \leq 0.00 \mathrm{I} \text { ) } \\
\text { (except in the fingers), in SSc patients } \\
\text { - The \% of the reduction in skin stiffness varied in the different Rodnan sites and in different phases of } \\
\text { the disease. } \\
\text { - There was a statistically significant change in the local Rodnan score only in the upper arm ( } \mathrm{p} \text {-value } \\
=0.046 \text { ) and forearm ( } \mathrm{p} \text {-value }=0.026 \text { ) }\end{array}$ \\
\hline $\begin{array}{l}\text { Chen } \\
(2020)^{44}\end{array}$ & $\mathrm{CC}$ & $\begin{array}{l}44 \text { (22dcSSc, } \\
221 \mathrm{lcSSc})\end{array}$ & 22 & $\begin{array}{l}\text { - Both Ultrasound-ST and skin stiffness were significantly higher in SSc patients } \\
\text { ( } \mathrm{p} \text {-value }<0.00 \mathrm{I}) \text { and even higher in those with dcSSc, than in controls. } \\
\text { - No clear correlation could be established between ultrasound-determined skin } \\
\text { thickness and stiffness at the same site. } \\
\text { - Ultrasound-skin thickness correlated well with histological skin thickness ( } r=0.6926, p \text {-value = } \\
0.009) \text { in the forearm }(n=135 S c)\end{array}$ \\
\hline $\begin{array}{l}\text { Flower } \\
(2020)^{61}\end{array}$ & $\mathrm{CC}$ & $\begin{array}{l}53 \text { (45lcSSc, } \\
8 \mathrm{dcSSc})\end{array}$ & 15 & $\begin{array}{l}\text { - ST (hand/forearm) and SWE (finger/hand) correlated with local mRSS at some sites. } \\
\text { - Subclinical abnormalities in ST, echogenicity and SWE were present in clinically uninvolved SSc skin. } \\
\text { - Changes in SWE were sometimes apparent, despite objectively normal ST. } \\
\text { - ST, SWE and local mRSS correlated strongly with collagen quantification } \\
\text { (rho } 0.697,0.709,0.649 \text { respectively). }\end{array}$ \\
\hline
\end{tabular}

Abbreviations: CC, case-control study; CS, cross-sectional study; mHC, age- and gender-matched healthy controls; SWV, shear wave velocity; ARFI, acoustic radiation force impulse; SWE, shear wave elastography; ST, skin thickness P, prospective study; mRSS, modified Rodnan skin score; dcSSc, diffuse cutaneous systemic sclerosis; IcSSc, limited cutaneous systemic sclerosis; SSc, systemic sclerosis. 

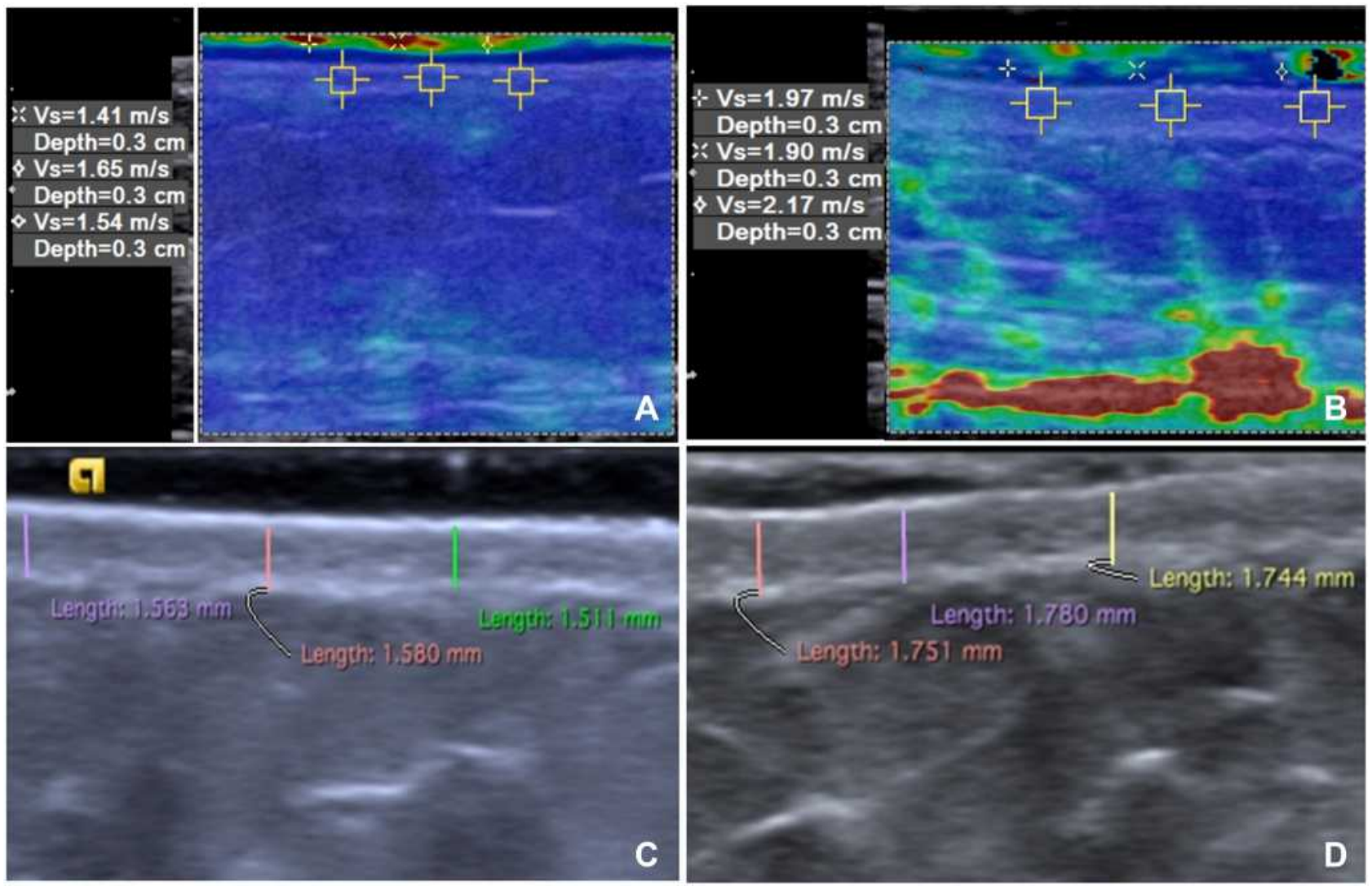

Figure 2 Shear-wave elastography, 8- $\mathrm{MHz},(\mathbf{A}$ and $\mathbf{B})$ and high-frequency ultrasound, $\mathbf{1 8}-\mathrm{MHz}(\mathbf{C}$ and $\mathbf{D})$ at the abdomen in a healthy control (A and $\mathbf{C})$ and a patient with systemic sclerosis (B and $\mathbf{D})$. Mean of three shear-wave velocity values was $1.7 \mathrm{~m} / \mathrm{s}(\mathbf{A})$ and mean dermal thickness was $1.55 \mathrm{~mm}$ in the control $(\mathbf{C})$, and $2.2 \mathrm{~m} / \mathrm{s}$ (B) and $1.76 \mathrm{~mm}(\mathbf{D})$ in the patient. The shear-wave velocities' values are displayed in a quantitative data box, at the left side of the image. Higher shear-wave velocity values indicate higher tissue stiffness. The colour scale indicate the stiffness of all tissues within the region of interest. (red=hard tissue; blue=soft tissue).

Note: Figure courtesy of Tânia Santiago.

\section{Recent Acquisitions in the Use of Ultrasound in the Study of Digital Ulcers in Systemic Sclerosis}

The investigation of digital ulcers (DU) in SSc patients has been successfully carried out by musculoskeletal ultrasound (5-18 MHz) and high-frequency (35 MHz) ultrasound, that have provided objective measurements $^{41,63}$ (Table 4). It has been demonstrated that DU ultrasound is feasible for various ulcer types, including those on the fingertips, overlying the extensor (dorsal) aspects of the hands and underlying subcutaneous calcinosis ${ }^{41,63}$ (Figure 3).

Table 4 Recent Milestones in the Study of Cutaneous Ulcers Analysed by Ultrasound in Systemic Sclerosis

\begin{tabular}{|l|l|l|l|l|}
\hline First Author & $\begin{array}{l}\text { Study } \\
\text { Type }\end{array}$ & SSc Patients (n) & $\begin{array}{l}\text { Control } \\
\text { Population }\end{array}$ & Summary of Results \\
\hline $\begin{array}{l}\text { Suliman et al } \\
(2018)^{41}\end{array}$ & CS & $\begin{array}{l}\text { II patients with ulcerated } \\
\text { and non-ulcerated lesions }\end{array}$ & None & $\begin{array}{l}\text { A 5-18 MHz ultrasound probe was used } \\
\text { Ulcerated lesions had a greater surface area than non-ulcerated lesions } \\
(55.5 \mathrm{vs} \mathrm{I2} \mathrm{mm2),} \mathrm{depth} \mathrm{(median} 2 \mathrm{~mm} \text { vs } 0 \mathrm{~mm}) \text {,and power Doppler signal } \\
(3 \mathrm{vs} 0 \text { patients) }\end{array}$ \\
\hline $\begin{array}{l}\text { Hughes et al } \\
(2017)^{63}\end{array}$ & CS & $\begin{array}{l}\text { II patients with SSc and } \\
\text { I5 with DU }\end{array}$ & None & $\begin{array}{l}\text { DU HUS (35 MHz) was feasible and well tolerated by patients. Most of } \\
\text { them were "classifiable" allowing for the measurement of the DU width } \\
\text { and depth. The mean (SD) DU depth and width was 0.99 (0.45) and 5.74 } \\
(2.16) \mathrm{mm} \text {, respectively }\end{array}$ \\
\hline
\end{tabular}

Abbreviations: CC, case-control study; CS, cross-sectional study; DU, digital ulcers; HUS, high-frequency ultrasound; SSc, systemic sclerosis. 

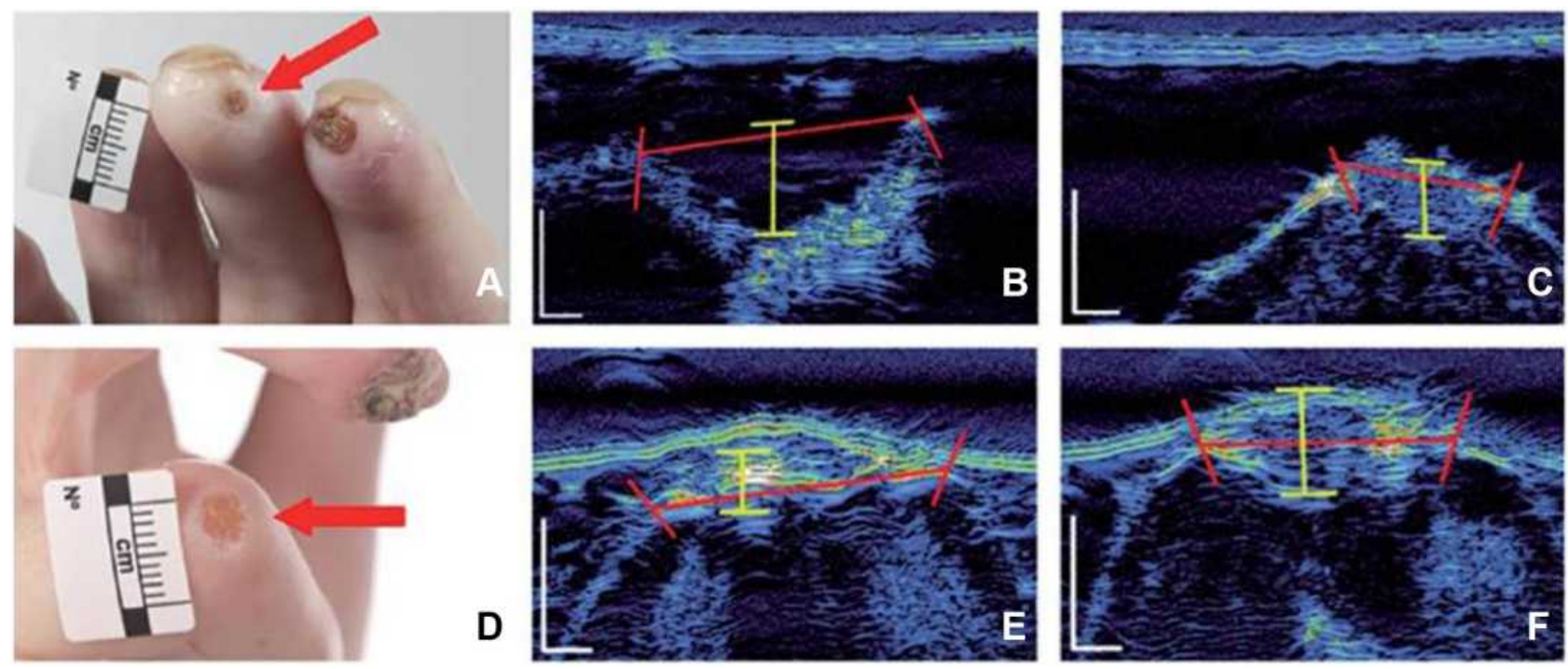

Figure 3 Digital ulcer ultrasound. Fingertip DU (A) and extensor aspect (D) (with the DU indicated by a red arrow). DU using high-frequency ultrasound images of the "long" (B) and "short" axis. Measurements (B and C and E and F) can be obtained of the ulcer width (red bars) and depth (yellow bars).

Notes: Adapted with permission from Hughes M, Moore T, Manning J, Dinsdale G, Herrick AL, Murray A. A pilot study using high-frequency ultrasound to measure digital ulcers: a possible outcome measure in systemic sclerosis clinical trials? Clin Exp Rheumatol. 2017;35 Suppl 106(4):218-219. @ Clinical and Experimental Rheumatology. ${ }^{63}$

Ultrasound may well provide a solution to solving many of the major changes intrinsic to the assessment of DU, also in clinical trials on SSc-associated vasculopathy. ${ }^{64}$ One such example is the difficulty in defining DU even in the hands of experts. ${ }^{65,66}$ Furthermore, deeper assessment may be hampered by the fact that lesions are often covered by hypertrophic tissue, eg, eschar, which can obscure the depth and/or extent of the wound base. ${ }^{65,66}$ Indeed, Hughes et al pilot study ${ }^{63}$ reports the average DU width and depth as being approximately $6 \mathrm{~mm}$ and $1 \mathrm{~mm}$, respectively, evidencing the challenge DU assessment poses by visual inspection alone. Suliman et $\mathrm{al}^{41}$ reported on the potential clinical utility of ultrasound in helping to differentiate between DU from non-DU lesions. Ulcer depth, surface dimensions (width and area) and volume have also been applied to DU measurement. ${ }^{41,63,67}$

The evidence currently available supports the fact that ultrasound is able to help in SSc DU assessment, as it is responsive to change. However, further studies are required on its validity and reliability. Furthermore, HUS may well provide new insights into the pathogenesis of ulcers, including infection, such as that done by colorDoppler activity. ${ }^{41}$

In summary, the studies carried out to date are very encouraging, as they support a potential role for ultrasound in the evaluation of DU burden in SSc patients. Considering that ultrasound is widely used in modern rheumatology practice, with the above steps, DU HUS could be a relatively easily adoptable, non-invasive method able to make an objective assessment of DU morphology and extent and to provide novel insights into DU pathogenesis. ${ }^{68}$

Moreover, as the use of ultrasound is now commonplace in modern rheumatology practice, is may also be of use as a non-invasive objective assessment tool to evaluate the morphology and extent of DU and may even provide new information on DU pathogenesis.

\section{Conclusions}

The present review emphasises the promising role ultrasonography plays in the assessment of SSc patients in the light of the technological advancements made and its wide availability. It also supports the need for further and more detailed assessments of SSc patients, aimed at earlier and quicker diagnosis, a more reliable disease monitoring and treatment, as well as the detection of early complications. Future goals should focus on standardizing measurement methods so as to create an open database for data comparison. All of which would allow for a better and deeper understanding of the various pathological phases and increase the specificity (comparison between healthy subjects and other diseases) and the sensitivity of HUS, that is necessary to spread its use in daily practice and clinical trials. 


\section{Acknowledgment}

The authors thank Prof. Barbara Wade for her linguistic advice.

\section{Disclosure}

The authors report no conflicts of interest in this work. No specific funding was received from any bodies in the public, commercial, or not-for-profit sectors, to carry out the work described in this manuscript. The authors declare that the research was carried out without any commercial or financial relationship that could be construed as a potential conflict of interest.

\section{References}

1. Smith V, Scirè CA, Talarico R, et al. Systemic sclerosis: state of the art on clinical practice guidelines. RMD Open. 2018;4(1):e000782.

2. Hughes M, Bruni C, Ruaro B, Confalonieri M, Matucci-Cerinic M, Bellando-Randone S. Digital ulcers in systemic sclerosis. Presse Med. 2021;50(1):104064.

3. Hughes M, Bruni C, Cuomo G, et al. The role of ultrasound in systemic sclerosis: on the cutting edge to foster clinical and research advancement. J Scleroderma Relat Disord. 2020.

4. Czirják L, Foeldvari I, Muller-Ladner U. Skin involvement in systemic sclerosis. Rheumatology (Oxford). 2008;47(5):44-45.

5. Clements PJ, Hurwitz EL, Wong WK, et al. Skin thickness score as a predictor and correlate of outcome in systemic sclerosis: high-dose versus low-dose penicillamine trial. Arthritis Rheum. 2000;43 (11):2445-2454.

6. Steen VD, Medsger TA Jr. Improvement in skin thickening in systemic sclerosis associated with improved survival. Arthritis Rheum. 2001;44(12):2828-2835.

7. Clements PJ, Lachenbruch PA, Ng SC, Simmons M, Sterz M, Furst DE. Skin score. A semiquantitative measure of cutaneous involvement that improves prediction of prognosis in systemic sclerosis. Arthritis Rheum. 1990;33(8):1256-1263.

8. Ruaro B, Soldano S, Smith V, et al. Correlation between circulating fibrocytes and dermal thickness in limited cutaneous systemic sclerosis patients: a pilot study. Rheumatol Int. 2019;39(8):1369-1376.

9. Cutolo M, Ruaro B, Montagna P, et al. Effects of selexipag and its active metabolite in contrasting the profibrotic myofibroblast activity in cultured scleroderma skin fibroblasts. Arthritis Res Ther. 2018;20 (1):77.

10. Wick G, Grundtman C, Mayerl C, et al. The immunology of fibrosis. Annu Rev Immunol. 2013;31(3):107-135.

11. Bhattacharyya S, Wei J, Varga J. Understanding fibrosis in systemic sclerosis: shifting paradigms, emerging opportunities. Nature Rev Rheumatol. 2012;8(1):42-54.

12. Cutolo M, Damjanov N, Ruaro B, Zekovic A, Smith V. Imaging of connective tissue diseases: beyond visceral organ imaging? Best Pract Res Clin Rheumatol. 2016;30(4):670-687.

13. Rodnan GP, Lipinski E, Luksick J. Skin thickness and collagen content in progressive systemic sclerosis and localized scleroderma. Arthritis Rheum. 1979;22(2):130-140.

14. LeRoy EC, Meedsger TA Jr. Criteria for the classification of early systemic sclerosis. J Rheumatol. 2001;28(7):1573-1576.

15. Khanna D, Furst DE, Clements PJ, et al. Standardization of the modified Rodnan skin score for use in clinical trials of systemic sclerosis. J Scleroderma Relat Disord. 2017;2(1):11-18.
16. Kaldas M, Khanna PP, Furst DE, et al. Sensitivity to change of the modified Rodnan skin score in diffuse systemic sclerosis-assessment of individual body sites in two large randomized controlled trials. Rheumatology. 2009;48(9):1143-1146.

17. Czirják L, Nagy Z, Aringer M, Riemekasten G, Matucci-Cerinic M, Furst DE. The EUSTAR model for teaching and implementing the modified Rodnan skin score in systemic sclerosis. Ann Rheum Dis. 2007;66(7):966-999.

18. Kaloudi O, Bandinelli F, Filippucci E, et al. High frequency ultrasound measurement of digital dermal thickness in systemic sclerosis. Ann Rheum Dis. 2010;69(6):1140-1143.

19. Moore TL, Lunt M, McManus B, Anderson ME, Herrick AL. Seventeen-point dermal ultrasound scoring system - a reliable measure of skin thickness in patients with systemic sclerosis. Rheumatology. 2003;42(12):1559-1563.

20. Sulli A, Ruaro B, Alessandri A, et al. Correlation between nailfold microangiopathy severity, finger dermal thickness and fingertip blood perfusion in systemic sclerosis patients. Ann Rheum Dis. 2014;73 (1):247-251.

21. Hesselstrand R, Scheja A, Wildt M, Akesson A. High-frequency ultrasound of skin involvement in systemic sclerosis reflects oedema, extension and severity in early disease. Rheumatology. 2008;47 (1):84-87.

22. Alexander H, Miller DL. Determining skin thickness with pulsed ultrasound. J Invest Dermatol. 1979;72(1):17-19.

23. Santiago T, Santiago M, Ruaro B, Salvador MJ, Cutolo M, da Silva JAP. Ultrasonography for the assessment of skin in systemic sclerosis: a systematic review. Arthritis Care Res (Hoboken). 2019;71 (4):563-574.

24. Ruaro B, Sakellariou G, Cutolo M, Iagnocco A. Well-trained sonographers are worth their weight in gold: ultrasound in systemic sclerosis. Rheumatology (Oxford). 2018;57(11):1883-1884.

25. Santiago T, Ruaro B, Cutolo M, Santiago M, Salvador MJ, da Silva JAP. Has the role of skin ultrasound for Systemic sclerosis been defined? Arthritis Care Res (Hoboken). 2019;71:695-696.

26. Abignano G, Del Galdo F. Quantitating skin fibrosis: innovative strategies and their clinical implication. Curr Rheumatol Rep. 2014;16(3):404.

27. Delle Sedie A, Riente L. Ultrasound in connective tissue diseases. Clin Exp Rheumatol. 2014;32(80):S53-60.

28. Ihn H, Shimozuma M, Fujimoto M, et al. Ultrasound measurement of skin thickness in systemic sclerosis. Br J Rheumatol. 1995;34 (6):535-538.

29. Ruaro B, Sulli A, Bernero E, Cimmino MA, Paolino S, Cutolo M. Identification of subclinical skin involvement by high frequency ultrasound in systemic sclerosis patients. Arthritis Rheumatol. 2015;67(10):234.

30. Sulli A, Ruaro B, Smith V, et al. Subclinical dermal involvement is detectable by high frequency ultrasound even in patients with limited cutaneous systemic sclerosis. Arthritis Res Ther. 2017;19(1):61.

31. Ruaro B, Sulli A, Pizzorni C, et al. Correlations between blood perfusion and dermal thickness in different skin areas of systemic sclerosis patients. Microvasc Res. 2018;115(3):28-33.

32. Ruaro B, Pizzorni C, Paolino S, et al. Correlations between nailfold microvascular damage and skin involvement in systemic sclerosis patients. Microvasc Res. 2019;125(4):103874.

33. Ruaro B, Sulli A, Smith V, et al. The impact of transducer frequency in ultrasound evaluation of subclinical skin involvement in limited cutaneous systemic sclerosis patients. Clin Exp Rheumatol. 2019;119 (4):147-148.

34. Porta F, Kaloudi O, Garzitto A, et al. High frequency ultrasound can detect improvement of lesions in juvenile localized scleroderma. Modern Rheumatology. 2014;24(5):869-873.

35. Hoffmann K, Gerbaulet U, El-Gammal S, Altmeyer P. 20-MHz B-mode ultrasound in monitoring the course of localized scleroderma (morphea). Acta Derm Venereol Suppl (Stockh). 1991;164(3):3-16. 
36. Cosnes A, Anglade MC, Revuz J, Radier C. Thirteen-megahertz ultrasound probe: its role in diagnosing localized scleroderma. $\mathrm{Br}$ $J$ Dermatol. 2003;148(7):724-729.

37. Li SC, Liebling MS, Haines KA, et al. Initial evaluation of an ultrasound measure for assessing the activity of skin lesions in juvenile localized scleroderma. Arthritis Care Res (Hoboken). 2011;63(5):735-1342.

38. Iagnocco A, Kaloudi O, Perella C, et al. Ultrasound elastography assessment of skin involvement in systemic sclerosis: lights and shadows. J Rheumatol. 2010;37(8):1688.

39. Di Geso L, Filippucci E, Girolimetti R, et al. Reliability of ultrasound measurements of dermal thickness at digits in systemic sclerosis: role of elastosonography. Clin Exp Rheumatol. 2011;29(6):926-932.

40. Ophir J, Cespedes I, Ponnekanti H, Hazdi Y, Li X. Elastography: a quantitative method for imaging the elasticity of biological tissues. Ultrason Imaging. 1991;13(2):111-134.

41. Suliman YA, Kafaja S, Fitzgerald J, et al. Ultrasound characterization of cutaneous ulcers in systemic sclerosis. Clin Rheumatol. 2018;37 (6): $1555-1561$.

42. Li H, Furst DE, Jin H, et al. High-frequency ultrasound of the skin in systemic sclerosis: an exploratory study to examine correlation with disease activity and to define the minimally detectable difference. Arthritis Res Ther. 2018;20(1):181.

43. Naredo E, Pascau J, Damjanov N, et al. Performance of ultra-highfrequency ultrasound in the evaluation of skin involvement in systemic sclerosis: a preliminary report. Rheumatology (Oxford). 2020;59(7):1671-1678.

44. Chen C, Cheng Y, Zhu X, et al. Ultrasound assessment of skin thickness and stiffness: the correlation with histology and clinical score in systemic sclerosis. Arthritis Res Ther. 2020;22(1):197.

45. Arisi M, Lorenzi L, Incardona $P$, et al. Clinical, histological and high-frequency ultrasonographic evaluation $(50 \mathrm{MHz})$ of morphoea treated with ultraviolet A1 phototherapy. Clin Exp Dermatol. 2019;44 (3):270-276.

46. Cosnes A, Anglade MC, Revuz J, et al. Thirteen-megahertz ultrasound probe: its role in diagnosing localized scleroderma. $\mathrm{Br}$ J Dermatol. 2003;148(4):724-729.

47. Florez-Pollack S, Kunzler E, Jacobe T. H. Morphea: current concepts. Clin Dermatol. 2018;36(4):475-486.

48. Murray AK, Moore TL, Manning JB, et al. Non-invasive imaging of localised scleroderma for assessment of skin blood flow and structure. Acta Derm Venereol. 2016;96(5):641-644.

49. Nezafati KA, Cayce RL, Susa JS, et al. 14-MHz ultrasonography as an outcome measure in morphea (localized scleroderma). Arch Dermatol. 2011;147:1112-1115.

50. Pérez M, Zuccaro J, Mohanta A, et al. Feasibility of using elastography ultrasound in pediatric localized scleroderma (Morphea). Ultrasound Med Biol. 2020;46(12):3218-3227.

51. Ranosz-Janicka I, Lis-święty A, Skrzypek-Salamon A, et al. An extended high frequency ultrasound protocol for assessing and quantifying of inflammation and fibrosis in localized scleroderma. Skin Res Technol. 2019;25(3):359-366.

52. Weibel L, Theiler M, Howell KJ, et al. Prospective evaluation of treatment response and disease reversibility of paediatric localized scleroderma (morphoea) to steroids and methotrexate using multi-modal imaging. J Eur Acad Dermatol Venereol. 2020;34(7):1609-1616.

53. Wortsman X, Wortsman J, Sazunic I, Carreno L. Activity assessment in morphea Using color Doppler ultrasound. J Am Acad Dermatol. 2011;65:942-948.
54. Cannaò PM, Vinci V, Caviggioli F, et al. Technical feasibility of real-time elastography to assess the peri-oral region in patients affected by systemic sclerosis. J Ultrasound. 2014;17(4):265-269.

55. Çildağ S, Çildağ MB. The relationship between the degree of skin fibrosis by sonoelastography and the degree of pulmonary involvement in scleroderma. Turk J Med Sci. 2017;47(5):1555-1559.

56. Hou Y, Zhu QL, Liu H, et al. A preliminary study of acoustic radiation force impulse quantification for the assessment of skin in diffuse cutaneous systemic sclerosis. $J$ Rheumatol. 2015;42 (3):449-455.

57. Santiago T, Alcacer-Pitarch B, Salvador MJ, Del Galdo F, Redmond AC, da Silva JA. A preliminary study using virtual touch imaging and quantification for the assessment of Skin stiffness in systemic sclerosis. Clin Exp Rheumatol. 2016;Suppl 100 (5):137-141.

58. Liu H, Hou Y, Zhu QL, et al. A preliminary study of skin ultrasound in diffuse cutaneous systemic sclerosis: does skin echogenicity matter? PLoS One. 2017;12(3):e0174481.

59. Yang Y, Wang L, Yan F, et al. Determination of normal skin elasticity by using real-time shear wave elastography. $J$ Ultrasound Med. 2018;37:2507-2516.

60. Sobolewski P, Maślińska M, Zakrzewski J, et al. Applicability of shear wave elastography for the evaluation of skin strain in systemic sclerosis. Rheumatol Int. 2020;40:737-745.

61. Flower VA, Barratt SL, Hart DJ, et al. High frequency ultrasound assessment of systemic sclerosis skin involvement: intra-observer repeatability and relationship with clinician assessment and dermal collagen content. J Rheumatol. 2020;1:jrheum.200234.

62. Santiago T, Santiago M, Coutinho M, Salvador MJ, Da Silva JAP. How much of skin improvement over time in systemic sclerosis is due to normal ageing? A prospective study with shear-wave elastography. Arthritis Res Ther. 2020;22(1):50.

63. Hughes M, Moore T, Manning J, Dinsdale G, Herrick AL, Murray A. A pilot study using high-frequency ultrasound to measure digital ulcers: a possible outcome measure in systemic sclerosis clinical trials? Clin Exp Rheumatol. 2017;35 Suppl 106 (4):218-219.

64. Li W, Frech TM. The critical need for accurately defining digital ulcers in scleroderma. $J$ Scleroderma Relat Disord. 2017;2 (2):69-71.

65. Hughes M, Roberts C, Tracey A, Dinsdale G, Murray A, Herrick AL. Does the clinical context improve the reliability of rheumatologists grading digital ulcers in systemic sclerosis? Arthritis Care Res (Hoboken). 2016;68(9):1340-1345.

66. Hughes M, Tracey A, Bhushan M, et al. Reliability of digital ulcer definitions as proposed by the UK Scleroderma Study Group: a challenge for clinical trial design. J Scleroderma Relat Disord. 2018;3(2):170-174.

67. Frech T, Pierce J, Stoddard G, McNeill C, Radic M, Reems J. Amniotic membrane dressings provide an effective treatment for systemic sclerosis digital ulcers. Arthritis Rheumatol. 2019;71 (suppl):10.

68. Hughes M. Response to 'Ultrasound characterization of cutaneous ulcers in systemic sclerosis'. Clin Rheumatol. 2018;37(7):2013. 


\section{Publish your work in this journal}

Open Access Rheumatology Research and Reviews is an international, peer-reviewed, open access journal publishing original research, reports, editorials, reviews and commentaries on all aspects of clinical and experimental rheumatology in the clinic and laboratory including the following topics: Pathology, pathophysiology of rheumatological diseases; Investigation, treatment and management of rheumatological diseases; Clinical trials and novel pharmacological approaches for the treatment of rheumatological disorders. The manuscript management system is completely online and includes a very quick and fair peer-review system, which is all easy to use. Visit http://www.dovepress.com/testimonials.php to read real quotes from published authors. 